Review

\title{
Posttraumatic Stress Disorder among Motor Vehicle Accident Victims
}

\author{
Marina Yuabova ${ }^{1}$, Michael Parrinello ${ }^{2}$ \\ ${ }^{1}$ La Guardia Community College, City University of New York, NY, USA \\ ${ }^{2}$ Northport Veterans Administration Medical Center, NY, USA
}

Received 5 March 2013, Accepted 20 March 2013

(C) 2013, Yuabova M., Parrinello M.

(C) 2013, Russian Open Medical Journal

Abstract: Motor vehicle accidents (MVA) have been a leading contributor to posttraumatic stress disorder (PTSD). Given the high rate of MVA incidents, it is of crucial importance to detect and diagnose PTSD in primary care. Assessing PTSD requires detecting and treating physiologic responses associated with MVA incidents. Responses such as elevated heart rate and blood pressure following an incident as well as psychological processes have been found to predict the likelihood of developing PTSD months or years after the occurrence. Screening for PTSD requires the implementation of multiple assessment tools to accurately detect the presence of PTSD. Clinicians chose assessment tools based on scales used to screen for anxiety, social dysfunction, somatic complaints and depression. Indeed, it cannot be overstated that clinicians must conduct early assessment and diagnosis of PTSD while evaluating the multiple factors that impact upon whether or not an individual will develop PTSD after a MVA.

Keywords: motor vehicle accidents, posttraumatic stress disorder

Cite as Yuabova M, Parrinello M. Posttraumatic Stress Disorder among Motor Vehicle Accident Victims. Russian Open Medical Journal 2013 ; 2: 0206.

Correspondence to Dr. Marina Yuabova. Address: 31-10 Thompson Avenue, Long Island City NY 11101 Phone: 15167910626 E-mail: marinayuabova@yahoo.com

Morbidity in the U.S. is majorly caused by accidents involving motor vehicles and therefore it makes vehicles one of the leading causes of deaths in the country with 3.5 million reported victims annually [1]. The government closely monitors motor vehicle accidents (MVA) because they cause many issues to their victims apart from increased deaths such as psychological issues that are severe among many other issues [2,3]. Some studies that were conducted in 2004 have MVAs as among major causes of PTSD among victims affected by the accidents [4]. Over 50 million casualties that result from accident due to motor vehicles in each calendar period. 28 victims in a total of 1000 victims that are affected usually turn out to have posttraumatic stress disorder (PTSD) with stress being one of the symptoms exhibited. Following this high number of PTSD victims that result from MVA, it is necessary to diagnose the disorder early so that primary care can be given early with the victim receiving medication early [5]. Intervening in PTSD cases early is important because it enables the victims to utilize diagnostic instruments that are cost effective, simple and reliable [6]. As discussed in the literature, predictors, assessment and establishment of factors that are closely related to PTSD are necessary in order to reduce the mortality of affected victims.

J.G. Beck et al. carried out a survey that wanted to ascertain the existence of various symptoms of PTSD among patients that are affected by accidents from motor vehicles in various parts in the U.S. In the study, they sampled respondents that were accompanied by emotional distress hence suffering from PTSD [7]. The survey established that patients in the adaptive coppers group depicted few or less features of PTSD such as anxiety and depression as compared to the dysfunction and adaptive categories. From the outcome of the study, it was concluded that it was easy for patients in the dysfunction and interpersonally distressed groups to have trauma and therefore develop PTSD especially after being a victim of MVA.

In another study conducted by Frommberger et al. on the prediction of PTSD using immediate reactions from an accident, a sample of 179 respondents were sampled [8]. The sampled respondents were MVA victims admitted in various hospitals. The findings of the study established that PTSD cases developed in patients with serious injuries as compared to patients that had minor injuries. Some of the symptoms exhibited by such patients included anxiety and depression that were predisposing factors to their long stay in hospital as compared to patients with minor injuries [9]. Recovered memory is a significant issue related to trauma. The recovery memory refers to memory that has been dissociated or repressed as a result of their traumatizing effects.

PTSD is characterized by other warning sign that include peritraumatic dissociation (PTD) and acute stress disorder (ASD) that are very common in victims of accidents from motor vehicles in the United States. In a study conducted by Bryant and Harvey to establish the differences in gender regarding PTSD, ASD and PTD, 171 victims were used as a representative sample for the entire population of MVA victims [10]. The survey involved examination of ASD among the victims for a one-month period that 
immediately followed the accident. The conclusion of the study point towards occurrence of ASD especially among $8 \%$ and $23 \%$ of the male and female victims respectively with the others being children or other age groups. When PTSD was observed among the respondents for a period of 6 months, $57 \%$ and $92 \%$ of males and females respectively turned positive for the disorder.

The conclusions of the study were pegged on the outcomes since it was concluded that the best predictor of PTSD among female victims was peri-traumatic dissociation, which was not so well revealed mainly by the male victims that were sampled in the study, but not by their opposed gender, the females. The discrepancies in gender regarding the signs could be explained by differences in reaction and biological make up among the two gender groups, although this does not imply that gender is also a significant factor that determines the prevalence of the disorder.

According to B.M.McDermott and A. Cvitanovich, psychopathology is common among victims that have suffered from accidents resulting from motor vehicles. In their study on the same, the prevalence of the condition was high among such patients and therefore there is a high correlation between the existence of the condition and availability of PTSD [11]. In a survey conducted by Harvey and Bryant, it was established that psychopathology among victims of accidents from motor vehicles was high similar to cases of PTSD with the correlation of the two being realized [12]. Ehlers et al. conquered with other researchers in other studies when they identified PTSD predictors as trauma severity, dissociation and threat perception that are experienced when one suffers from PTSD [13]. Therefore, as indicated by all these studies, there are common predictors of PTSD that can be easily identified by observation of the patients suffering from the disorder. Following their significance, the studies help in early diagnosis of PTSD among victims of accidents from motor vehicles.

\section{Discussion of PTSD}

In order to manage the PTSD condition, it is necessary that it is determined early using the symptoms. The assessment of the disorder can be done through various means. In a study carried out by E.B. Blanchard et al. to ascertain the PTSD condition, it was revealed that a heart rate that is elevated instantly after the incidence of an accident is a pointer in the direction of development of PTSD by the victim in various perspectives across all levels [14]. Using a sample of 74 accident patients that were admitted in hospital and observed for some time, it was established that patients that had a high heart rate were less likely to have developed PTSD 13 months after the accident. The findings of the study were also contrary to findings from previous studies that had indicated exactly the opposite. However, the discrepancies in the outcomes could be attributed to the dissimilarities in the data that was obtained from the study including the disparities in the composition information [15]. Despite the differences, it was confirmed that increased heart rate after occurrence of an accident can be used to as a confirmatory test for PTSD.

To test for PTSD, researcher and medical practitioners can also utilize physiological responsiveness. As noted by Veazey et al. in their study on existing differences in physiological receptiveness among fatalities that had developed PTSD and those that had not, there is are significant relationships between development of chronic PTSD and subsyndromal PTSD among others especially non-PTSD victims [16]. Following these findings, it was concluded that situational physiological responsiveness to traumatic situations is also a significant instrument in establishing PTSD among MVA victims.

Establishment of PTSD can also be through the cognitive process that involves development especially in children. In one of the studies that were conducted to establish the use of cognitive process in establishing existence of PTSD, a sample of 59 children and adolescent MVA victims were studied with researchers discovering that PTSD is closely associated with maladaptive appraisal. Other cognitive processes that can be effectively used to determine the existence of PTSD as indicated by the study are memory procedures and subjective threats because it is worth noting that the findings of the study are significant for early intervention on PTSD among patients involved in accidents [17].

There is another technique that some doctors to use to diagnose PTSD that is called Recovery memory therapy, which is closely associated with the dissociative identity disorder. The utilization of the technique identifies hypnosis as the major cause of the disorder in which the affected victim shows two identities and disturbing personalities. In addition, the patient has intrusive traumatizing thoughts that are accompanied by loss of memory [18].

\section{Factors Associated with PTSD}

PTSD has been linked with many factors that affect patients in trauma such as biological, psychological, and physiological factors as noted by Kupchik et al. Who conducted a survey among PTSD patients in order to establish the incidence of depression and anxiety, the problems exhibited greater than when compared to patients that do not have the disorder [19]. R. Mayou et al. supported the findings [20]. Other warning signs that were found to be shown by patients suffering from PTSD were alexithymia, which is the adaptive manner through which patients deal with anxiety and despair as compared to a maladaptive manner that is a prompting factor to pressure among many patients [21]. Although some studies established that gender is a risk factor to PTSD [22, 23], other studies such as M. Kupchik et al. and $S$. Jeavons found out that there is no relationship between gender and PTSD [19, 24]. Similarly, no similarity among traumatic experience in the past, premorbid psychiatric conditions and PTSD exists [23]. These studies contradict other studies which found that PTSD is significantly associated with past history of psychiatric morbidity $[25,26]$, anxiety disorders, psychiatric treatment and past experience of motor vehicle accidents $[12,18]$.

\section{Anxiety Screening and Diagnosis}

Assessment of past history of trauma is accompanied by several psychological issues that may affect the assessment process with one of them being post-traumatic stress disorder. Post-traumatic stress disorder refers to conditions that result after a person has been exposed to a traumatizing event or situation [27]. Often, accident victims are exposed to events that traumatize their lives. In normal situation, these feelings die after sometime. However, for the case of post-traumatic stress disorder, these feelings persist for a long time such that the victim fails to function in the same way as before [28]. During the assessment of past history of trauma, symptoms of post-traumatic stress disorder are sometimes encountered. In this case, the victim is found to be reliving the traumatic events such that he or she is in constant distress. At the same time, the person dissociates from the rest and may not be interested in activities going on around him or her. 
Furthermore, post-traumatic stress disorder increases the arousal of the victim. This means that the victim exhibits excessive emotions. At the same time, the person becomes irritable. He or she exhibits outburst of anger, difficult in concentration, and feeling of withdrawal. During the assessment process of the history of child trauma, psychologists encounter these problems [29].

Another psychological issue encountered during the assessment of the history of trauma is false memory. False memory is an imprecise reminiscence of an event that did not occur in life. In this case, the victim is made to think that a particular event happened to him or her yet it did not. Such events traumatize the victim to the point of seeking professional help from psychologists. False memories results in many circumstances. For instance, a victim may have been an audience where a scary story was being narrated. At other times, a person may distort the information witnessed during childhood to connote a traumatizing event [30].

\section{Conclusion}

Victims suffering from various traumas in life are likely to suffer from PTSD including those that survive from accidents resulting from motor vehicles. Despite the high number of patients that suffer from the disorder, most cases of victims from accident related trauma go unreported with patients succumbing to death. This literature review has revealed the predisposing factors of PTSD as well as the importance of early diagnosis that may lead to faster healing rather than worsening the conditions of sickness. Therefore, it is necessary that all people involved in the treatment of the disorder be knowledgeable in predictors of the condition so that they can keep on saving lives of MVA victims.

Conflict of interest: We have received no funding from any commercial or private sources. We have no commercial interest in the writing of this review article.

\section{Reference}

1. Butler DJ, Moffic HS, Turkal NW. Post-traumatic stress reactions following motor vehicle accidents. Am Fam Physician 1999; 60: 524531.

2. Blaszczynski A, Gordon K, Silove D, Sloane D, Hillman K, Panasetis P. Psychiatric morbidity following motor vehicle accidents: a review of methodological issues. Compr Psychiatry 1998; 39: 111-121. (PMID: 9606576) (doi: 10.1016/S0010-440X(98)90069-4)

3. Hepp U, Moergeli H, Buchi S, Bruchhaus-Steinert H, Kraemer B, Sensky $\mathrm{T}$, et al. Post-traumatic stress disorder in serious accidental injury: 3year follow-up study. Br J Psychiatry 2008. 192(5): 376-383. (PMID: 18450664) (doi: 10.1192/bjp.bp.106.030569)

4. Khouzam HR, Donnelly NJ. Posttraumatic stress disorder: safe, effective management in the primary care setting. Postgrad Med 2001; 110: 60-2, 67-70, 77-8. (doi: 10.3810/pgm.2001.11.1048) (PMID: 11727653)

5. Gayle Beck J, Gudmundsdottir B, Shipherd JC. PTSD and emotional distress symptoms measured after a motor vehicle accident: Relationships with pain coping profiles. I Psychopathol Behav Assess 2003; 25(4): 219-227. (PMID: 16518453) (PMCID: PMC1388076)

6. Wittchen HU, Kessler RC, Beesdo K, Krause P, Höfler M, Hoyer J. Generalized anxiety and depression in primary care: prevalence, recognition, and management. J Clin Psychiatry 2002; 63(8): 24-34. (PMID: 12044105)
7. Beck JG, Coffey SF, Palyo SA, Gudmundsdottir B, Miller LM, Colder CR. Psychometric properties of the Posttraumatic Cognitions Inventory (PTCl): a replication with motor vehicle accident survivors. Psychol Assess 2004; 16: 289-298. (PMID: 15456384) (PMCID: PMC1360225)

8. Frommberger UH, Stieglitz RD, Nyberg E, Schlickewei W, Kuner E, Berger M. Prediction of posttraumatic stress disorder by immediate reactions to trauma: a prospective study in road traffic accident victims. Eur Arch Psychiatry ClinNeurosci 1998; 248: 316-321. (PMID: 9928912) (doi: 10.1007/s004060050057)

9. National Comprehensive Cancer Network. Distress management. Clinical practice guidelines. J Nat/ Comp Cancer Network 2003; 1: 344374. (PMID: 19761069)

10. Bryant RA, Harvey AG. Gender differences in the relationship between acute stress disorder and posttraumatic stress disorder following motor vehicle accidents. Aust N Z J Psychiatry 2003; 37: 226-229. (PMID: 12656964) (doi: 10.1046/j.1440-1614.2003.01130.x)

11. McDermott BM, Cvitanovich A. Posttraumatic stress disorder and emotional problems in children following motor vehicle accidents: an extended case series. Aust N Z J Psychiatry 2000; 34: 446-452. (PMID: 10881968) (doi: 10.1046/j.1440-1614.2000.00753.x)

12. Harvey AG, Bryant RA. Predictors of acute stress following motor vehicle accidents. J Trauma Stress 1999; 12(3): 519-525. (PMID: 10467559) (doi: 10.1023/A:1024723205259)

13. Ehlers A, Mayou RA, Bryant B. Psychological predictors of chronic posttraumatic stress disorder after motor vehicle accidents. J Abnorm Psychol 1998; 107(3): 508-519. (doi: 10.1037/0021-843X.107.3.508) (PMID: 9715585)

14. Blanchard EB, Hickling EJ, Galovski T, Veazey C. Emergency room vital signs and PTSD in a treatment seeking sample of motor vehicle accident survivors. J Trauma Stress 2002; 15(3): 199-204. (PMID: 12092911) (doi: 10.1023/A:1015299126858)

15. Mitchell AJ. Pooled results from 38 analyses of the accuracy of distress thermometer and other ultra-short methods of detecting cancerrelated mood disorder. J Clin Oncol 2007; 25: 4670-4681. (PMID: 17846453) (doi: 10.1200/JCO.2006.10.0438)

16. Veazey $\mathrm{CH}$, Blanchard EB, Hickling EJ, Buckley TC. Physiological responsiveness of motor vehicle accident survivors with chronic posttraumatic stress disorder. Appl Psychophysiol Biofeedback 2004; 29(1): 51-62. (PMID: 15077464)

17. Jacobsen PB, Donovan KA, Trask PC, Fleishman SB, Zabora J, Baker F, et al. Screening for psychological distress in ambulatory cancer patients. Cancer 2005; 103: 1494-1502. (PMID: 15726544) (doi: 10.1002/cncr.20940)

18. Koren D, Arnon I, Klein E. Acute stress response andposttraumatic stress disorder in traffic accident victims: Aone-year prospective, follow-up study. Am J Psychiatry 1999; 156: 367-373. (PMID: 10080550)

19. Kupchik M, Strous RD, Erez R, Gonen N, Weizman A, Spivak B. Demographic and clinical characteristics of motor vehicle accident victims in the community general health outpatient clinic: A comparison of PTSD and non-PTSD subjects. Depress Anxiety 2007; 24 : 244-250. (PMID: 17001628) (doi: 10.1002/da.20189)

20. Mayou R, Bryant B, Ehlers A. Prediction of psychological outcomes one year after a motor vehicle accident. Am J Psychiatry 2001; 158 : 1231-1238. (PMID: 11481156) (doi: 10.1176/appi.ajp.158.8.1231)

21. Alvarez WA, Shipko S. Alexithymia and posttraumatic stress disorder. $J$ Clin Psychiatry 1991; 52: 317-319. (PMID: 2071564)

22. Hoffman BM, Zevon MA, D'Arrigo MC, Cecchini TB. Screening for distress in cancer patients: the NCCN rapid-screening measure. Psychooncology 2004; 13: 792-799. (doi: 10.1002/pon.796) (PMID: 15386639)

23. Ursano RJ, Fullerton CS, Epstein RS, Crowley B, Kao TC, Vance K, et al. Acute and chronic posttraumatic stress disorder in motor vehicle accident victims. Am J Psychiatry 1999; 156: 589-595. (PMID: 10200739) 
24. Jeavons S. Predicting who suffers psychological trauma in thefirst year after a road accident. Behav Res Ther 2000; 38: 499-508. (PMID: 10816908) (doi: 10.1016/S0005-7967(99)00073-X)

25. Irish L, Ostrowski SA, Fallon W, Spoonster E, Dulmen Mv, Sledjeski EM, et al. Trauma history characteristics and subsequent PTSD symptoms in motor vehicle accident victims. J Trauma Stress 2008; 21(4): 377384. (PMID: 18720390) (doi: 10.1002/jts.20346)

26. Kuch K, Cox BJ, Evans RJ. Posttraumatic stress disorder and motor vehicle accidents: a multidisciplinary overview. Can J Psychiatry 1996; 41: 429-434. (PMID: 8884031)

27. Akizuki N, Akechi T, Nakanishi T, Yoshikawa E, Okamura M, Nakano T, et al. Development of a brief screening interview for adjustment disorders and major depression in patients with cancer. Cancer 2003; 97: 2605-2613. (PMID: 12733160) (doi: 10.1002/cncr.11358)

28. Ransom S, Jacobsen PB, Booth-Jones M. Validation of the distress thermometer with bone marrow transplant patients. Psychooncology 2006; 15: 604-612. (PMID: 16208733) (doi: 10.1002/pon.993)

29. Trask $P C$, Paterson A, Riba $M$, Brines $B$, Griffith $K$, Parker $P$, et al. Assessment of psychological distress in prospective bone marrow transplant patients. Bone Marrow Transplant 2002; 29: 917-925. (PMID: 12080358) (doi: 10.1038/sj/bmt/1703557)

30. Roth AJ, Kornblith AB, Batel-Copel L, Peabody E, Scher HI, Holland JC. Rapid screening for psychological distress in men with prostate carcinoma: A pilot study. Cancer 1998; 82: 1904-1908. (PMID: 9587123)

Authors:

Marina Yuabova - RN, MSN, BSN, FNP, DNP, Assistant Professor, Health and Science Department, La Guardia Community College, City University of New York, NY, USA;

Michael Parrinello - PhD, DNP, MS, PNP, FNP-BC, MBA, MA, BSN, BS, RN Northport Veterans Administration Medical Center, NY, USA. 